European Commission's point is that the environment varies widely in Europe, and that organisms whose release is considered safe in one state may be harmful in another. The proposed safeguard is that all member states will have the right to protest when experimental releases anywhere are planned, but the Royal Commission evidently believes that this will not suffice. The same problem will of course arise elsewhere, which is why there is a case for giving European institutions a stronger role in the licensing procedure than that now planned.

\section{Can heresy be real?}

INSERM has done the only decent thing by confirming $\mathrm{Dr}$ Jacques Benveniste in his post. But what happens now?

THESE have been wretched months for Dr Jaques Benveniste, the director of INSERM's unit for the study of immunology and allergy, otherwise called INSERM 200. During the past few months, as part of the research council's routine quadriennial review of its establishments, (see page 89) two separate committees have trudged through his laboratory, each of them mixing scepticism with admiration in their reports. The admiration is natural enough. Since 1981, when Benveniste became the unit's director, his laboratory has produced a substantial amount of solid research, which has been published in reputable journals. But, sadly, Benveniste is best known for what seems to be an aberration - the assertion that some biological reagents retain their activity even when indefinitely diluted, well beyond the point at which all molecules should have disappeared. Outwardly, these two roles conflict. INSERM deserves credit for recognizing that, in science, either the concept of heresy is meaningless or, otherwise, heresy cannot be an excommunicable offence.

The Benveniste business is complicated, as readers of this journal know only too well. A year ago, Nature published a paper (E. Davenas et al.330, 816; 1988) from Benveniste's group, following it with an almost equally contentious document, based on a visit to INSERM 200, which was critical of the procedures by which data had been gathered and interpreted (Nature 334, 287; 1988). Since then, Benveniste says, the statistical treatment of the high-dilution data has been improved - and the phenomenon persists. Benveniste has nevertheless acceded to an earlier demand by INSERM that his highdilution experiments should not consume public resources. He now also agrees to refrain from conducting science through the daily press and to keep an "open mind" to alternative interpretations of his high-dilution data. He remains convinced that his observations point to a real phenomenon, and protests that freedom in science is jeopardized by the pressures to which he has been subjected.

Nobody will dispute people's right to be wrong. Mistakes happen all the time. It is also proper that people should persist with their beliefs in the face of scepticism. Where would the heliocentric hypothesis be had Galileo not done so? There is also an honourable tradition that laboratory directors, often appointed because of their achievements in some field, should provide their colleagues with encouragement and resources while themselves embarking on more adventurous if risky projects.

Benveniste's essential difficulty is that, even after the unusual attention paid to his claims, few seem openly to have followed his line of investigation. (Nature, in the past year, has been sent for publication a single paper reporting similar observations with a different system, now with its authors for further clarification, but may well have discouraged others by its treatment of Benveniste's contribution.) Even the three collaborating laboratories quoted by Benveniste a year ago have been publicly silent. Although truth in science cannot be determined by casting votes, Benveniste's failure to recruit open support within the scientific community should be discouraging.

INSERM, an excellent organization with no inclination to be classed with the Spanish inquisition in the suppression of heterodoxy, has resolved its dilemma excellently. Considerations other than freedom in research determine the relationship between a research organization and its laboratory directors. Benveniste cannot be faulted as an administrator and motivator - his laboratory last year was as enthusiastic for its orthodox as for its unorthodox work. Nor should it be a consideration that a single director holding views widely disbelieved could damage the reputation of French science (as some have darkly suggested): after a decade of remarkable progress within France and internationally, only narrow chauvinists could believe that. But it does make sense that Benveniste should now be asked, with breathtaking openness, not to rock INSERM's boat uncomfortably by over-zealous and even surreptitious advocacy of his cause.

The truth about heresy in science, after all, is that nobody can prove that heretical beliefs are in any sense wrong. The standard complaint against the popperian view of science - that there is no such thing as truth can also be turned inside out, to show that, in the fields in which hypotheses cannot yet be tested, there is no such thing as being wrong. That, in a court of philosophical law, would be Benveniste's best defence. In the real world, his best defence is simpler: people who believe that water can have a memory and things like that, but who are otherwise reputable researchers, have a right to expect that their colleagues will listen to them courteously. Correspondingly, they also have a duty to listen when their critics say that, if that is the hypothesis, this is how it can be tested convincingly. But Benveniste and his critics have usually dealt with each other by pretending that the others do not exist. Should they not now, in the interests of good manners if not of truth, break with precedent? Benveniste is wrong about the memory of water, but has won the right to expect that people will put him straight. 